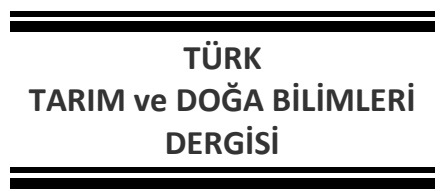

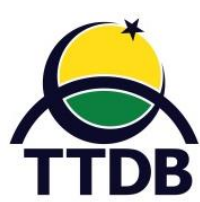

www.dergipark.gov.tr/turkjans

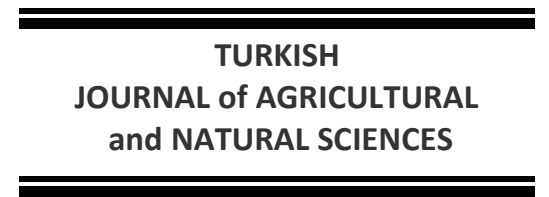

Araştırma Makalesi

\title{
Laurus Nobilis L., Silybum Marianum L., Nigella Sativa L. ve Prunus Cerasus L.'den Soguk Pres Yöntemi İle İzole Edilen Esansiyel Yağ Bileşenlerinin Antimikrobial ve Antioksidan Aktiviteleri
}

\author{
Ömer ERTÜRK ${ }^{1 *}$, Gülçin AYDIN ${ }^{1}$, Melek ÇOL AYVAZ ${ }^{2}$ \\ ${ }^{1}$ Ordu Üniversitesi, Fen Edebiyat Fakültesi, Moleküler Biyoloji ve Genetik Bölümü, Ordu, Türkiye \\ ${ }^{2}$ Ordu Üniversitesi, Fen Edebiyat Fakültesi, Kimya Bölümü, Ordu, Türkiye \\ *Sorumlu yazar: oseerturk@hotmail.com, onerturk@odu.edu.tr
}

Geliş Tarihi: 20.05.2019 Düzeltme Geliş Tarihi: 26.02.2020 Kabul Tarihi: 26.02.2020

\begin{abstract}
Özet
Bu çalışmada, Laurus nobilis L., Silybum marianum L., Nigella sativa L. ve Prunus cerasus L.'in kimyasal bileşimleri, antimikrobiyal ve antioksidan özellikleri ve bunların ana bileşenleri belirlenmiştir. Yağların ve bileşenlerin antimikrobiyal aktivitesi, agar seyreltme ve difüzyon disk plakları metotları kullanılarak bir standart referans suşları paneline ve gıda kaynaklı ve patojenik bakteri suşlarının bir paneline karşı belirlenmiştir. Uçucu yağ numunelerinin antioksidan aktiviteleri, FRAP, $\mathrm{DPPH}^{\bullet}$ ve $\mathrm{ABTS}^{\bullet}{ }^{+}$analizleri kullanılarak değerlendirildi. Uçucu yağ analizleri GC/MS ile yapılan $L$. nobilis $S$. marianum, $N$. sativa. ve $P$. cerasus 'in izole edilen uçucu yağ bileşenlerinde sırasıyla 65, 119, 46 ve 40 bileşen GC-MS ile analiz edildi. GC/MS analizi, yağların ana bileşenlerinin, monoterpen hidrokarbonlar ve fenolik monoterpenler olduğunu gösterdi, ancak bu bileşiklerin konsantrasyonu, incelenen yağlar arasında büyük ölçüde değişmiştir. FRAP ve ABTS testlerinin sonuçlarında, özellikle, soğuk pres yöntemiyle elde edilen defne tohumu yağ numunesi, önemli ölçüde daha yüksek antioksidan aktiviteye sahiptir. Sonuç olarak, sonuçlar L., nobilis S. marianum , N. sativa. ve $P$. cerasus'dan (soğuk pres) elde edilen yağların, veya bileşiklerin her biri nispeten güçlü antibakteriyal ve antifungal aktivite sergilemiştir. Bu nedenle, gıda endüstrisinde antimikrobiyal ve antioksidan maddeler olarak kullanım için uygun olabilirler. Gıda sistemlerindeki bileşenlerin bazıları gıda kaynaklı bakteri üremesini önleyebilir ve işlenmiş gıdaların raf ömrünü uzatabilir.
\end{abstract}

Anahtar kelimeler: Antimikrobiyal aktivite, Antioksidan, Esansiyel yağ

\section{Antimicrobial and Antioxidant Activity of Essential Oil Components Isolated By Cold Press From Laurus nobilis L., Silybum marianum L., Nigella sativa L. and Prunus cerasus L.}

\begin{abstract}
In this work, the chemical composition, antimicrobial and antioxidant properties of Laurus nobilis L., Silybum marianum L., Nigella sativa L. and Prunus cerasus L. and their main components were determined. The antimicrobial activity of the oils and components was determined against a panel of standard reference strains and multiple strains of food-derived and pathogenic bacteria, using the agar dilution and diffusion disc plates methods. Essential oil analyzes were performed by GC/MS. Antioxidant activities of essential oil samples were evaluated using FRAP, DPPH ${ }^{\bullet}$ and $\mathrm{ABTS}^{\bullet+}$ assays. The essential oils isolated from L.nobilis, S. marianum, N. sativa and P.cerasus were analysed by GC-MS that $65,119,46$ and 40 constituents were identified, respectively. The $\mathrm{GC} / \mathrm{MS}$ analysis showed that the major constituents of the oils were monoterpene hydrocarbons and phenolic monoterpenes, but the concentration of these compounds varied greatly among the oils examined. In the results of FRAP and ABTS assays, especially in the case of bay seed, oil samples obtained by cold press method have significantly higher antioxidant activity. In conclusion, the results indicate that the oils of obtained from $L$. nobilis, S.marianum, $N$. sativa and $P$. cerasus cold press or compounds exhibited relatively strong antibacterial and antifungal activity. Therefore, they could be suitable for using as antimicrobial and antioxidative agents in food industry. Some of components in food systems to may prevent the growth of foodborne bacteria and extend shelf-life of processed foods.
\end{abstract}

Keywords: Antimicrobial activity, Antioxidant, Essential oil 


\section{Giriş}

Bitkiler insanlı̆ı̆ın var oluşundan beri hayatın vazgeçilmez temel kaynaklarından biridir. Illkçağlardan beri insanlar bitkileri tanımışlar, çeşitli amaçlarla kullanmışlar ve tanıtmaya çalışmışlardır (Baytop, 1984). Hastalıkların tedavisinde tıbbi bitkilerin kullanımı, insanoğlunun yerleşik hayata geçmesiyle eş zamanlı gerçekleşen eski bir gelenek olmuştur. Bugüne kadar uçucu yağlarda 2000'den fazla kimyasal bileşenin bulunduğu görülmüştür ki, bunların en önemlileri terpenlerin yanında alkoller, aldehitler, esterler, fenoller, azot ve kükürt içeren bileşikleri içermektedirler (Ceylan, 1983). Uçucu yağlar bitkilerden başlıca damıtma, anfloraj (soğukta katı yağ ile özütleme), maserasyon (sıcakta katı yağ ile özütleme), çözücü ile özütleme ya da mekanik sıkma yöntemleri ile elde edilmektedir. Anfloraj yöntemi az miktarda uçucu yağ içeren ya da kolayca bozulabilen, taç yaprak gibi narin bitki organlarına; sıkma yöntemi ise, uçucu yağı kalın dış kabuklarında barındıran turunçgiller meyvelerine uygulanmaktadır (Dorman ve Deans, 2000). Uçucu yağlar spazm çözücü, irrite edici, antiseptik, antifungal, antiviral ve antimikrobiyal özellikler göstermektedirler. Uçucu yağların antibiyotik ve antiseptik özellikleri bakteriler, küf mantarları ve mayalara karşı olabilmektedir. Terpenlerin uçucu yağların ana bileşenleri olması, bu sınıf bileşiklerin de biyolojik özelliklerinin araştırılmasına yol açmıştır. Örneğin, kekik yağında bulunan bir timol ve karvakrol, fenolden 20 kat daha antiseptiktir ve diş macunlarında kullanılır. Bu bileşikler hem antioksidan hem de antibiyotik özelliklere sahip olup karaciğeri koruyucu ve iyileştirici etkilerinin yanında kalp kası üzerinde de olumlu etkileri vardır (Arkan, 2008). Limonen ve $\alpha$-pinen antibakteriyel ve antifungal etki göstermektedir. Melisa yağında bulunan sitral, uçuk tedavisinde; gül yağında bulunan geraniol ise cildi dengelemek ve canlandırmak için kozmetik ürünlerinde kullanılan terpen sınıfı bileşiklerdir. Uçucu yağların biyolojik ve tıbbi kullanımları yanında kozmetik, parfümeri, böcek kovucu, yapıştıııcı, lokal anastezik, aromaterapi, gıda ve temizlik malzemelerinde, vb. birçok alanda kullanımı, bu tür bileşiklerin ekonomik boyutta da önemini arttırmıştır (Baytop, 1984).

Ülkemizde çörek otunun 12 farklı türü yetiştirilmektedir. Bunların tohumları halk hekimliğinde ve baharat olarak daha yaygın bir şekilde kullanılmaktadır. Çörek otunun kimyasal bileşimi; bitkinin hasat mevsimine, çeşidine, yetiştirildiği iklime ve bölgeye göre farklılık göstermektedir (Al-Jassir, 1992). Özel ve ark., (2008)'nın aktardığına göre, Lauraceae familyasının takriben 45 cins ve 1000 kadar türü, Laurus cinsinin ise $L$. nobilis ve $L$. canariensis Willd. olmak üzere iki türü bulunmaktadır. Defne (L. nobilis L.)'nin ülkemizde tek türü bulunmaktadır. Defne yapraklarının antibakteriyel terletici, ağrı kesici, antiseptik ve mide rahatsızlıklarını giderici, diyabeti tedavi edici, migreni önleyici, halsizlik, hazımsızlık, aybaşı düzensizlikleri, romatizma ve uykusuzluk hastalıklarına iyi geldiği değişik araştırmalarla ortaya konmuştur (Baytop, 1984).

S. marianum L. bitkinin kullanılan kısımları meyveleridir (Cardui mariae fructus). Etken maddeleri: Silimarin ismi verilen flavonolignan karışımı; majör bileşik silibin taşır. Tohumunda flavonoit yapıdaki taksifoline de rastlanmıştır. Tüm bitkide, marianin ve marianosit A-B adlı triterpenoitler bulunur. S. marianum tohumları \%2030 oranında sabit yağ içermekte olup; bu yağın $\% 60$ ' l linoleik, \%30'u oleik ve \%9'u palmitik asittir (Wagner ve ark., 1968; Wallace ve ark., 2003). Vişne meyvesi yüksek oranda antioksidan madde bulundurması sebebiyle fonksiyonel gıdalar arasında önemli bir yer tutmaktadır. 100g kabuklu vişne çekirdeği $76.5 \mathrm{~g}$ sert kabuk ve $23.5 \mathrm{~g}$ yenebilir çekirdek içi ihtiva eder. Vişne çekirdeğinin kimyasal kompozisyonu yapılan araştırmalarda kütlece \%46.6 toplam karbonhidrat, \%29.3 protein, \%17 toplam yağ, \%3.9 nem, ve \%3.1 kül olarak tespit edilmiştir. (P. cerasus L) Vişne çekirdeğinin ise kütlece $\% 76.5^{\prime}$ ini sert kabuk, \%23.5'ini yenebilir çekirdek içi oluşturur. Vişne meyvesinin fonsiyonel özellikleri arasında antioksidan, antienflamatuar, antikarsinojen, antidiabetik, antinörodejeneratif aktiviteler ve dolaylı yoldan ortaya çıkan sinerjik etkileşimler sayılabilir (Damar ve Ekşi, 2012). Bu çalışmada soğuk pres yöntemiyle elde edilmiş bazı eterik yağların antimikrobiyal ve antioksidan özelliklerine bakılacaktır.

\section{Materyal ve Yöntem \\ Uçucu Yağların Temini}

Araştırmada kullanılan $L$. nobilis L., $S$. marianum L., N.sativa $L$. ve $P$. cerasus $L$., bir gıda katkı maddesi tedarikçisinden (Gıda Maddeleri İstanbul, Türkiye) en çok kullanılan ürünlerin listesinden seçilmiştir. Seçilmiş esansiyel yağlar sırasıyla LnO'lar, SmO'lar, NsO'lar ve PcO'lar şeklinde geçerli olan ortak isimleri ile kodlanmıştır. $\mathrm{Bu}$ soğuk pres esansiyel yağlar (EO) kullanıncaya kadar oda sıcaklığında sarı cam bir şişede güneş ışığından uzakta tutuldu. Numuneler ODU Fen Edebiyat Moleküler Biyoloji ve Genetik bölümü Mikrobiyoloji Laboratuarına getirilmiştir ve çalışılmıştır.

\section{Çözgenler}

Uçucu yağların antimikrobiyal aktivitesi etanol ve hekzan çözeltisi ile seyreltilerek belirlenirken, antioksidan aktivite ise sadece etanol 
çözücüsü ile oluşturulan ekstraktlar üzerinde belirlenmiştir.

\section{Besiyerleri}

Antimikrobiyal aktivitenin belirlenmesinde kullanılacak olan disk difüzyon ve ağar dilüsyon yönteminde; bakteriler için Muller Hinton Agar, funguslar (mantarlar) için Saboraud Dextrose Ağar besiyerleri kullanılmıştır. Mikroorganizmaların üremesini sağlamak için Muller Hinton Broth ve Saboraud Dextrose Broth besiyerleri kullanılacaktır. Minimum inhibisyon konsantrasyonu çalışmasında yukarıda belirtilen agar besiyerleriyle birlikte, $1 / 4$ oranında Tris tamponu kullanılmıştır.

\section{Mikroorganizmalar}

Antibakteriyel etki belirlemede kullanılan mikroorganizmalar ; Pseudomonas aeruginosa ATCC ${ }^{\circledR} 27853$ Gram (-), Proteus vulgaris ATCC ${ }^{\circledR} 7829$ Gram (-), Escherichia coli ATCC ${ }^{\circledR} 25922$ Gram (-), Klebsiella pneumoniae ATCC $^{\circledR} 13883$ Gram (-), Listeria monocytogenes ATCC ${ }^{\circledR 7677}$ Gram (+), Clostridium perfringens ATCC 313124 Gram (-), Salmonella enteric ATCC 14028, Gram (-), Bacillus subtilis B209, Gram (+), Streptococcus mutans RSHE 676, Gram (+), Micrococcus luteus B1018, Gram (+), Staphylococcus aureus ATCC 6538 Gram (+), Yersinia enterocolitica ATCC ${ }^{\circledR} 27729$ Gram (-), Bacillus cereus ATCC $^{\circledR} 10876$ Gram (+), Candida albicans ATCC ${ }^{\circledR} 10231$, Aspergillus niger ATCC 9642.

\section{Disk difüzyon deneyi}

Antimikrobiyal aktivite yöntemi Ronald (1990)'a göre yapıldı. Her bir petri kabına bakteriler için MHA ortamı (Merck, $40 \mathrm{~mL}$ ) ve mantarlar ve mayalar için SDA ortamı (Oxoid, $40 \mathrm{~mL}$ ) döküldü. Tüm bakteri suşları MHB'de (Merck) 24 saat 37 ${ }^{\circ} \mathrm{C}$ 'de ve maya ve mantar suşları SDB'de (Difco) 27 ${ }^{\circ} C^{\prime}$ de 48 saat boyunca büyütülmüştür. Gece kültürleri, sıvı besiyeri ile seyreltildi ve son bakteri ve maya / mantar hücre konsantrasyonları, sırasıyla A $600 \mathrm{~nm}$ 'de spektrofotometrik olarak ölçülerek $1 \times 10^{8}$ ve $\quad 1 \times 10^{7}$ hücre $\mathrm{ml}^{-1}$ e ayarlandı. Her seyreltilmiş süspansiyondan $100 \mu \mathrm{L}$, petri kaplarına agar üzerine aktarıldı ve yayıldı. Daha sonra, 30-20 $\mu \mathrm{L} \mathrm{mg}^{-1}$ her bir uçucu yağ ekstraktını yüklemek için agar üzerine steril kağıt diskler (6 $\mathrm{mm}$ çap) yerleştirildi. Mantarlar ve mayalar için Nystatin ve bakteriler için Ampicillin ve Cephazolin pozitif kontrol olarak kullanıldı. Negatif kontrol olarak alkol ve hekzan kullanılmıştır. Petriler antibakteriyal ve antifungal aktiviteler için, $37^{\circ} \mathrm{C}$ 'de ve $28^{\circ} \mathrm{C}$ 'de 24 48 saat süreyle inkübasyona bırakıldı. Inkübasyondan sonra ortamda oluşan inhibisyon zonları, milimetre $(\mathrm{mm})$ olarak ölçülmüştür. Tüm testler üç kopya halinde yapıldı.

\section{Minimum inhibisyon konsantrasyonu}

Antimikrobiyal tarama için hafif modifikasyonlarla Vander Berghe ve Vietinck (1991) tarafından açıklanan Agar dilüsyon yöntemi kullanıldı. 96 gözlü mikrotiter plakalar yerine 24 gözlü doku kültürü (Corning) plakaları kullanıldı. Esansiyel yağ ekstraktları \% 70 etanol, fizyolojik Tris tamponu (Amresco 0826-500G) karışımı (1:4) içinde çözüldü ve $45^{\circ} \mathrm{C}$ 'de eşit miktarda $\% 3$ agar çözeltisi mantarlar için (Sabouraud Dextrose Agar (Oxoid) ile karıştırıldı. Bakteriler için Mueller Hinton Agar (Merck) kullanıldı. Uçucu yağ ekstresi örneklerinin her biri $100,50,25,12.5,6.25$ ve $3.125 \mathrm{mg} \mathrm{mL}^{-1}$ konsantrasyonlarında test edilmiştir, test çözeltilerinden her biri her gözede bulunan $400 \mu \mathrm{L}$ besiyer + tris tanponu olan karışıma aktarılmıştır. Doku kültürü plakası kuyusu çözünme işleminden sonra, her bir göz $10 \mu \mathrm{L}$ taze hazırlanmış $1 \times 10^{8}$ bakteri süspansiyonu, $1 \times 10^{7}$ mantar $\mathrm{ml}^{-1}$ aşılanmış ve $37-28{ }^{\circ} \mathrm{C}^{\prime}$ de $24-48$ saat inkübasyonda bırakılmıştır. Bakteri için pozitif kontrol olarak Ampicillin ve Cephazolin 100, 50, 25, 12.5, 6.25 ve $3.125 \mathrm{mg} \mathrm{ml}^{-1}$ ve mantarlar için Nystatin aynı şartlarda test edilmiştir. Bakteriyel ve mantar gelişimi, inkübasyon süresinden sonra stereo mikroskopta değerlendirilmiştir.

\section{GC/MS ile Uçucu Aroma Bileşen Analizi Ekstraksiyon Yöntemi}

Aroma maddeleri bileşiminin

belirlenmesinde Riu-Aumatell ve ark. (2004) tarafından geliştirilen yöntem modifiye edilerek kullanılmıştır. Buna göre, $20 \mathrm{~mL}$ Headspace viallerine üzerine $3 \mathrm{gr}$ esansiyel yağ örneği ilave edilmiş ve vortex ile $30 \mathrm{sn}$ karıştırılmıştır. $50{ }^{\circ} \mathrm{C}^{\prime}$ de fiber (SPME Fiberi)'de 40 dakika bekletildikten sonra GC-MS aletine (Shimadzu GCMS-QP2010) enjeksiyon yapılmıştır. Fiber her enjeksiyondan önce $200^{\circ} \mathrm{C}^{\prime}$ de 10 dakika koşullandırılmıştır. Kolon olarak Restek RTX-5 (30m x $0.25 \mathrm{~mm} \times 0.25 \mu \mathrm{m})$ kullanılmış, taşıyıcı faz olarak da Helyum'dan yararlanılmıştır. Kolon sıcaklığı, $40^{\circ} \mathrm{C}^{\prime}$ de 5 dakika bekledikten sonra, dakikada $4^{\circ} \mathrm{C}$ artırılarak $240^{\circ} \mathrm{C}^{\prime}$ ye çıkacak şekilde programlanmıştır.

\section{DPPH serbest radikal temizleme etkinliği}

Uçucu yağ numunelerinin DPPH serbest radikal temizleme aktivitesini belirlemek için, metanol içindeki DPPH çözeltisinin renk değişimi spektrofotometrik olarak izlendi. Bu amaçla, kararlı radikal olarak kullanılan $1 \mathrm{~mL} 0.4 \mathrm{mM}$ DPPH çözeltisinin absorbansı ilk önce 517 nm'de (A $A_{\text {kör }}$ ) ölçülmüştür. Diğer taraftan, DPPH çözeltisine \%2 oranında esansiyel yağ numuneleri eklendi ve oda sıcaklığında 30 dakika inkübasyondan sonra, son absorbans ölçüldü ve Anumune olarak kaydedildi. Uçucu yağ numunelerinin hidrojen atomunu veya 
elektron duyarlııklarını değerlendirmek için DPPH serbest radikal temizleme aktivitesi, aşağıdaki denklem kullanılarak hesaplandı (Kıvrak, 2018).

$$
\left.\% I=\left(A_{k o ̈ r}-A_{n \text { numune }}\right) 100 / A_{k o ̈ r}\right)
$$

\section{ABTS radikal temizleyici etkinliği}

Örneklerin toplam antioksidan aktivitesi, ABTS radikal katyonunun $\left(\mathrm{ABTS}^{\bullet+}\right)$ renginin çözülmesinin ardından da belirlendi (Re ve ark., 1999). Bu amaçla ABTS radikal katyon, ABTS çözeltisi ve potasyum persülfatın karıştırılmasıyla hazırlandı. Uçucu yağ numunelerinin her biri, 12-16 saat boyunca oksidasyon işleminden sonra $30{ }^{\circ} \mathrm{C}$ 'de dengelenen $A B T S$ radikal çözeltisine ilave edildi ve absorbansı, etanol ile seyreltilerek $734 \mathrm{~nm}$ 'de 0.7 'ye ayarlandı. ABTS ${ }^{\bullet+}$ örneklerin süpürme aktivitesi ( $\mu \mathrm{mol}$ TX g görnek) olarak hesaplandı.

\section{FRAP deneyi}

Ferrik indirgeyici antioksidan güç analizi, ucuz, tekrarlanabilir ve basit bir antioksidan aktivite belirleme yöntemidir. Bu çalışmada, uçucu yağ örneklerinin FRAP aktivitelerini belirlemek için Habib ve ark., (2013)'nın izlediği yol takip edildi. FRAP yöntemi, Fe (III) -TPTZ kompleksinin Fe (II) TPTZ'ye indirgenmesi ve elde edilen mavi rengin yoğunluğunun $595 \mathrm{~nm}$ 'de ölçülmesine dayanır (Oyaizu, 1986). Bu amaçla, test edilmeden ve karıştırılacak uygun miktarda numuneye analiz eklenmeden hemen önce taze hazırlanmış olan 1.2 $\mathrm{mL}$ FRAP reaktifi. $37^{\circ} \mathrm{C}$ 'de 30 dakika inkübasyondan sonra, absorbans ölçüldü. Sonuçlar, standart antioksidan troloks ile aynı deneysel koşullarla elde edilen standart kalibrasyon grafiği kullanılarak trolox eşdeğeri ( $\mu \mathrm{mol} \mathrm{TX} \mathrm{g}^{-1}$ numune) olarak hesaplandı.

\section{İstatistiksel analiz}

GraphPad Prism 5.0 programı, sitotoksisite eğrilerinin ve CC50'nin hesaplanmasında kullanılmıştır. Tüm veriler SPSS istatistik 17.0 yazılımı ile istatistiksel olarak değerlendirildi. Hipotez test yöntemleri, Duncan'ın yeni çoklu aralık testleri, post hoc veya çoklu karşılaştırma testleri tarafından takip edilen tek yönlü varyans analizini (ANOVA) içerir. $\mathrm{P}<0.05$ değeri istatistiksel olarak anlamlı farklar olarak kabul edildi (Motulsky, 2007).

\section{Bulgular}

L.nobilis (defne), S.marianum (deve dikeni), N.sativa, (çörek tohumu) ve $P$. cerasus (vişne tohumu) bitkilerinden soğuk pres yöntemiyle elde edilen esansiyel yağların antimikrobiyal aktivitesinin taranması sonucu elde edilen veriler çizelge 1.'de verilmiştir. Soğuk pres yöntemiyle elde edilen esansiyel yağlar etanol ve hekzan ile 10 ve $20 \mathrm{mg} \mathrm{ml}^{-}$
${ }^{1}$ konsantrasyonunda seyreltildi ve insan potojeni olan 12 bakteri ve 2 fungusa uygulandı. Genel olarak tüm esansiyel yağların hekzan seyreltikleri ethanol seyreltiklerine oranla daha fazla antimikrobiyal aktivite gösterdi. Kağıt filtre disk diffüzyon yöntemiyle uygulanan LEO (Laurus esansiyel oil) örneğinin hem etanol hemde hekzan seyreltikleri anlamlı bir antimikrobiyal etki gösterdi. Böylece, LEO tüm bakteri soylarının büyümesini engelledi ve 7.3 ila $16.9 \mathrm{~mm}$ arasında değişen bir inhibisyonu zonu çapı üretti. LEO, test edilen tüm bakterilere karşı en güçlü aktiviteyi gösterdi. Özellikle $L$. monocytoge, $C$. perfiringes ve $S$. enteritidis bakterilerine en etkili antibakteriyal etki gösterirken, C. albicans ve A.niger'e karşı da güçlü bir antifungal etki gösterdi. Böylece, L. nobilis EO, test edilen tüm Gram-negatif ve Gram-pozitif suşlara karşı antimikrobiyal etkinlik gösterdi. Genel olarak, esansiyel yağların ikisi Gram-pozitifliğe karşı Gram-negatif bakterilere göre daha aktifti. Hem alkol hemde hekzan ile seyreltilmiş 20 ve $30 \mathrm{mg} \mathrm{ml}^{-}$ ${ }^{1}$ NEO (N. sativa esansiyel oil) örneği in vivo önemli antimikrobiyal aktiviteler göstermiştir. Ancak, alkol ekstraktın etkisi (Çizelge 1.) anlamlı olmamakla

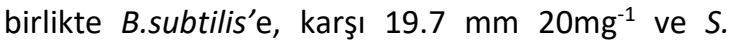

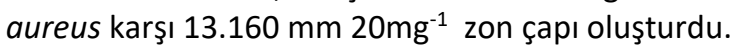
Bununla birlikte hekzan ile seyreltilen NEO, $B$.

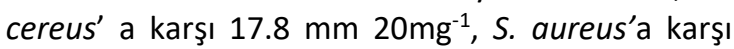
$14.6 \mathrm{~mm} 20 \mathrm{mg}^{-1}$ ayrıca en yüksek bir şekilde de A.niger ve $C$. albicans karşı ise sırasıyla $3.7 \mathrm{~mm}$ $20 \mathrm{mg}^{-1}$ ve $14.2 \mathrm{~mm} \mathrm{20mg}^{-1}$ değerinde ölçülen çap değerleri ile antifungal aktivite gösterirken, diğerleri için orta düzeyde bir antimikrobiyal etki gösterdi. Hekzan ve alkol ile elde edilen S.marianum esansiyel yağ ekstraktları tarafından sağlanan inhibisyon çapları, hekzan konsantrasyonları ile alkol orantılı değildir. SEO hekzan 20 ve $30 \mathrm{mg} \mathrm{ml}^{-1}$

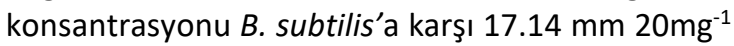

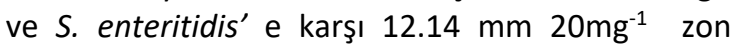
çapları oluşturmak suretiyle inhibisyon oluşturmuştur. Benzer bir şekilde $A$. niger ve $C$. albicans türlerine karşı da sırasıyla $12.32 \mathrm{~mm} 20 \mathrm{mg}^{-}$ 1 ve $13.22 \mathrm{~mm} 20 \mathrm{mg}^{-1}$ lik çap değerleriyle kaydedilen antifungal aktivite oluşturmuştur. SEO hekzan 20 ve $30 \mathrm{mg} \mathrm{ml}^{-1}$ konsantrasyonu azda olsa Gram (+) ve Gram (-) bakterilere karşı mikostatik olan ve fungal suşlara (C.albicans ve A.niger) karşı bakteriyostatik bir etkiye sahiptir.

Bununla birlikte $P$. cerasus (vişne tohumu esansiyel yağ) bitkilerinden soğuk press yöntemiyle elde edilen esansiyel yağların hem alkol hemde hekzan ile seyreltilmiş 20 ve $20 \mathrm{mg} \mathrm{ml}^{-1}$ antimikrobiyal aktivitesinin çok yüksek olmadığı görüldü. Gram pozitif $B$. subtilis Gram-negatif $L$. monocytoge ve $P$. vulgaris ayrica A.niger ve $C$. albicans mikrobiyal büyümesi yalnızca nispeten yüksek konsantrasyonlarda oldu. 
Soğuk pres yöntemiyle elde edilen esansiyel yağların içindeki ana bileşenler. N. sativa yağından Cymene <(\% 26.77), Limonen (\% 8.27) Linalool (\% 6.61) Okaliptol (\% 15.58) Thujene $<(\%$ 4.27) ve Carvacrol tespit edildi. Soğuk pres yöntemiyle elde edilen L.nobilis bitkisinin esansiyel yağların ana bileşenleri, Asetoin (\% 8.77), Pinen <> (\% 6.74), Phellandrene <> (\% 6.77), Myren (\% 4.36), Sabinene (\% 9.99) ve Ocimene $(\% 7,70)$ dir. Sabinene, Laurus nobilis'ten soğuk pres EO da en bol bulunan bileşendir. Ancak S.marianum yağından soğuk pres EO'nun ana bileşenleri Tridec-2 (E) -enal (\% 5.60), Asetilvaleril (\% 7.06), Fenetil alkol (\% 7.67), Etilen brassilat (\% 4.62) Angelat <izobütil-> (\% 18.42) ) ve Undecanal <2-metil-> (\% 6.13). Prunus cerasus'un soğuk pres EO'su benzaldehit (\% 4.79), Myrcene (\% 4.39), Cymene <(\% 5.19), Eucalyptol (\% 30.90), Isoborneol (\% 5.74). ve Carvacrol (\% 5.15). Çizelge 2,3,4,5'de tüm esansiyel yağların bileşim kompozisyonu görülmektedir.

Çalışmanın bir diğer kısmında ise kısmında Türkiye'nin farklı bölgelerinden toplanmış ve ticari olarak üretilen 4 farklı bitkinin soğuk pres yöntemlerle elde edilmiş uçucu yağ ekstraktlarının antioksidan aktiviteleri farklı metodlara dayanan yöntemlerle belirlenmeye çalışıldı. Gerçekleştirilen ölçümler ve yapılan hesaplamalar sonrasında soğuk pres yöntemlerle ile uçucu yağ ekstraktı hazırlanmış olan defne tohumu (L. nobilis)'in en yüksek oranda (\%40.76) DPPH radikallerini süpürme yeteneğine sahip olduğu tespit edilmiştir. \%30.74 oranında DPPH değeriyle de çörek otu $N$. sativa'nın sahip olduğu, deve dikeni S. marianum bitkisinin OE'sinin (\%12.04) DPPH değeri ve vişne tohumu Prunus cerasus' un OE'sinin DPPH değerinin olmadığı tespit edildi. Aynı ekstraktın ABTS testi ile belirlenenen ve elektron transferine dayanan antioksidan gücüde de 4 numune içinde en yüksek (63.93 $\mu \mathrm{mol} \mathrm{TX} \mathrm{g}^{-1}$ yağ) olarak saptanmıştır. Fesleğenin uçucu yağ ekstraktının hesaplanan FRAP değeri de soğuk pres yöntemi ile elde edilen deve dikeni uçucu yağları için tespit edilen en yüksek değere $\left(28.13 \mu \mathrm{mol} \mathrm{TX} \mathrm{g}^{-1}\right.$

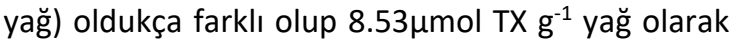
hesaplanmıştır. Çörek otu için bu değerler FRAP

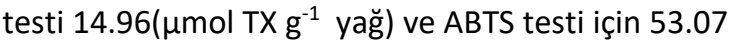

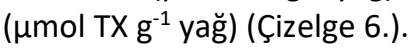

\section{Tartışma}

Anekdotik kanıtlar ve bitkilerin geleneksel olarak medikal anlamda kullanılması, hangi esansiyel yağların ve bitki özlerinin spesifik tıbbi durumlar için faydalı olabileceğini göstermek için bir temel sağlar. Geleneksel olarak, geleneksel antiseptiklerde yeni antimikrobiyal bileşiklerin potansiyel kaynakları olarak kullanılan bitkiler (Mitscher ve ark., 1987) doğal tedavilere olan ilginin yeniden dirilmesi ve etkin, güvenli, doğal ürünler için artan tüketici talebinin artması, bitkisel yağlar ve ekstrelere ilişkin nicel verilerin gerekli olduğu anlamına gelir. L. nobilis, S.marianum, N. sativa, ve $P$. cerasus bitkilerinden soğuk pres yöntemiyle elde edilen esansiyel yağların antimikrobiyal aktivite veileri çizelge $1^{\prime}$ de düzenlenmiştir. L. nobilis EO, tahlil edilen tüm Gram-negatif ve Gram-pozitif suşlara karşı antimikrobiyal etkinlik gösterdi. Derwich ve arkadaşlarının (2009) yaptığı bir araştırma, bu yağın $S$. aureus, $S$. intermedius ve $K$. pnömonisine karşı aktif olduğunu bildirmiştir. Dahası, Dadalioğlu ve Evrendilek (2004), Türkiye'den L. nobilis EO'nun E. coli O157: H7, L. monocytogenes, Salmonella typhimurium ve $S$. aureus'a karşı güçlü bir antimikrobiyal aktivite gösterdiğini bildirmişlerdir. Genel olarak, her iki LEO da Gram-pozitifliğe karşı Gram-negatif bakterilere göre daha aktiftir. N. sativa tohumunun, S. aureus, E. coli, Shigella spp. ve Vibrio chloerae gibi patojenlere karşı in vitro antibakteriyel etkinliğe sahip olduğunu belgeleyen çalışmalar bulunmaktadır (Rathee ve ark., 1982). N. sativa tohumlarının esansiyel yağı, Shigella spp., $V$. chloerae ve E. coli'nin, in vitro (Ferdous) çoklu ilaca dirençli (örneğin, ampisilin, co-trimoksazol ve tetrasiklin) izolatlara karşı etkili olmuştur. Çalışmada kullanılan esansiyal yağların sonuçları yapılan birçok çalışmayla desteklenmektedir. Silmarinin Gram (+) üzerindeki antibakteriyal etkisini göstermiştir (Polyak ve ark., 2007) ve bu bulgular bu maddenin diğer mikroorganizmalar üzerinde etkinliğini de teyit eder. S. marianum'un çiçek ve yapraklarının özleri karaciğer, dalak ve safra kesesi hastalıklarını tedavi etmek için yüzyıllar boyunca kullanılmıştır (Rainone, 2005). 1960'larda, Silymarin adlı bir flavonolignan karışımı, klinik çalışmaların çoğunun yapıldığı tohumdan ve meyve özlerinden izole edildi. Bulgulara dayanarak, S. marianum tohumları S. marianum'un şifalı bitki olarak önemini açıklayan flavonoid tanenler ve terpenoidler gibi önemli biyoaktif bileşikler içeriyordu. Flavonoidlerle zengin bitkilerin ekstralarının antimikrobiyal aktiviteye sahip olduğu bildirilmiştir (Tim ve Andrew, 2005). Yapılan bazı çalışmalarda P.cerasus meyve özütlerinin antimikrobiyal etkisi daha önce Kołodziejczyk ve ark., (2013) tarafından belgelenmiştir. Gram pozitif Listeria spp. Gramnegatif Salmonella ve E. coli O157: H7 büyümesi yalnızca yüksek konsantrasyonlarda (> $2500 \mathrm{mg} \mathrm{ml}^{-}$ $\left.{ }^{1}\right)$ azaltılırken Coccia ve ark. (2012), 2-6.6 mg ml-1 aralığında P.cerasus meyvesinin metanolik bir özütünün patojen bakterileri inhibe edici konsantrasyonları belirledi.

Bitki esansiyel yağlarının antibakteriyal, antifungal, antiviral, antioksidatif ve antimutajenik etkilerine yönelik elde edilen araştırma sonuçları genel olarak pozitif yöndedir. Son yıllarda, yüksek 
miktarda besin maddelerini içermesi nedeni ile soğuk pres metoduna olan ilgi artmıştır. Soğuk pres yağ ekstraksiyon esnasında herhangi bir şekilde sıcaklık ve kimyasal madde uygulaması olmayan bir prosestir (Kiralan ve ark., 2014). Her ne kadar soğuk pres yöntemi ile daha düşük verimliliklerde yağ elde ediliyor olsa da, çözücü ekstraksiyon ile gerçekleştirilen proseslerde olduğu gibi son üründe çözücü kalıntısına rastlama riski bulunmamaktadır (Lutterodt ve ark., 2010). Bahsedilen metotlar ile elde edilen yağların fizikokimyasal özellikleri karşılaştırıldığında soğuk pres yöntemi kullanılarak elde edilen yağların serbest yağ asidi gibi kalite parametrelerinde daha iyi sonuçlar verdiği görülmüştür. $\alpha, \beta, \gamma, \delta$ tokoferol değerleri ve sterol bileşikleri, toplam fenoller ve timokinon oranları daha yüksek bulunmuştur (Kiralan ve ark., 2014). Soğuk pres yağlarda bulunan fenolikler ve flavonoid gibi polifenol bileşikler de antimikrobiyal, antienflamatuvar, antitrombotik, antialerjik, antiaterojenik, antioksidan gibi teröpatik etki gösterirler (Balasundram ve ark., 2006). Soğuk pres yağ üretim prosesinin en önemli faktörü sıcaklık uygulanmamasıdır. Literatür bilgilerine dayanarak yağlı tohumlardan preslenerek yağ çıkarma işlemi $50{ }^{\circ} \mathrm{C}$ dereceyi geçmemelidir. Soğuk pres yöntemi sıcak pres ve ön ısıtma uygulanan pres yöntemlerine kıyasla daha düşük değerlerde serbest yağ asitlerine sahiptir (Balasundram ve ark., 2006).

Esansiyel yağlar Gram (-) ve Gram (+) bakteriler dahil, birçok mikroorganizma üzerine antibakteriyal etki göstermektedir. Örneğin esansiyel yağ bileşenlerinden izomerik fenol sınıfına ait olan karvakrol ve timol ile fenilpropanoid sınıfında yer alan sinnamaldehit, E.coli 0157 ve $S$. typhimurium üzerine antibakteriyal etki göstermektedir. Karvakrol ve timol, bakteri membranını parçalayarak membranla ilgili materyallerin hücre dışına çıkmasını sağlarken, terpenoidler ve fenilpropanoidlerin ise lipofilik özellikleri sayesinde bakteri duvarını delerek hücrenin daha iç kısımlarına ulaştıkları bildirilmiştir. Helandar ve ark., (1998) bazı bitki ekstraktlarının test mikroorganizması olarak kullanılan bazı Gram (+) ve Gram (-) bakteri ve maya suşlarına karşı inhibitör etkisi gösterdiğini tespit etmişlerdir. Sartoratto ve ark., (2004) ise 8 farklı aromatik bitkiden elde edilen uçucu yağların 11 farklı mikroorganizma üzerinde farklı derecelerde inhibitör etkisi gösterdiklerini bildirmişlerdir. Bir başka çalışmada, Mısır Sina Yarımadası'ndan toplanan $T$. santolinoides bitkisine ait uçucu yağların hem Gram (+), hem de Gram (-) bakterilere karşı antibakteriyal aktivite gösterdiği tespit edilmiştir (El-Shazly ve ark., 2002). Esansiyel yağların bileşenleri arasında aditif, antagonistik ve sinerjik etkileşimlerin olduğu da ileri sürülmüştür. Lambert ve ark., (2001), timol ve karvakrolün $S$. aureus ve $P$. aeruginosa üzerine etkilerini inceledikleri çalışmada, bu maddelerin beraber kullanıldıklarında tek başına kullanıldıklarından daha iyi bir etki gösterdiklerini bildirmişlerdir. Bazı bitki ekstraktları ve aktif bileşikleri gıda kaynaklı patojen küflere karşı doğal fungistatik ve/veya fungisidal etkili bileşiklere sahiptir. Antifungal etkide rol oynayan bileşikler, miktar ve dağılım açısından esansiyel yağ çeşidine göre farklılık göstermektedir (ilçim ve ark., 1998). Daha önce bildirildiği gibi, yağların gözlenen antioksidan aktiviteleri, karvakrol, timol ve linalool içeriği ile açılanabilir (El Hamdaoui ve ark., 2018). Elde edilen sonuçlara dayanarak, test edilen yağ örneklerinin gıda ve kozmetik ürünlerdeki oksidatif süreçleri azaltma kabiliyetine sahip olabileceği ve bu gibi ticari ürünlerdeki sentetik antioksidanların yerini almak için kullanılabileceği söylenebilir (Yuan ve ark., 2016). Bitkilerin sekonder metabolizmasının aromatik ve uçucu ürünleri olan ve yapraklarda ve doğal antioksidanlar olarak bulunabilen uçucu yağların kullanımı serbest radikallerin insan vücudundaki zararlı etkilerine karşı koruyabilir (Chou ve ark., 2018). Uçucu yağların ve kendi bileşenlerinin antioksidan kapasitesi, bugüne kadar birçok kez araştırılmış ve belgelenmiştir (Sarikurkcu ve ark., 2018). Lavandula türlerinin antioksidan aktiviteye sahip olduğu bilinmektedir (EI Hamdaoui ve ark., 2018). Özellikle kekikten çıkan EO, gıda koruyucu olarak dünyanın en yaygın kullanılan on EO'su arasındadır (Ehivet ve ark., 2011). Bu sonuçlara dayanarak, çeşitli aromatik bitkilerden elde edilen uçucu yağların, içermiş olduğu farklı ve etkin bazı bileşikler farklı alanlarda kullanılabilir. Uygun hidrofobikliği sayesinde, karvakrol ve bazı esansiyel yağ bileşenleri hücre zarında birikir. Hidrojen bağlama kabiliyeti ve proton salıverme kabiliyeti, hücre ölümü ile sonuçlanan zarın yapısal olarak modifikasyonuna neden olabilir. Buna karşılık, karvaril asetat, karvarol metil eterde ve diğerleri bazılarının serbest bir hidroksil grubunun olmaması, protonlarını değiştirmelerini, zar geçirgenliğinin değişmesi sonucu mikroorganizma büyüme inhibisyonunu indüklemelerini engelleyebilir. Genel olarak, incelenen yağların bileşimi ve özleri onların potansiyel antibakteriyal ajanlar olarak klinik izolatları karşı kullanılabilir.

Esansiyel yağlar her bileşenler için kabul edilemez olmasına rağmen, esansiyel yağların düşük toksisiteye sahip olduğu bilinen bir gerçektir. Fakat böylede olsa esansiyel yağlar aktif bileşenlerin toksisite çalışmalarının yapılması da gereklidir.

\section{Teşekkür}

Bu araştırma, Ordu Üniversitesi Bilimsel Araştırma Projeleri Koordinasyon Dairesi tarafından TF-1635 numaralı projeyle desteklenmiştir. Ordu 
Üniversitesi'ne ve Ordu Üniversitesi Merkez Araştırma Laboratuvarı'na maddi destekleri için teşekkür ederiz.

\section{Kaynaklar}

Al-Jassir, MS. 1992. Chemical Composition and Microflora of Black Cumin (Nigella sativa L.) Seeds Growing in Saudi Arabia. Food Chemistry, 45(4): 239-242.

Arkan, S. 2008. Karvakrol ve Timolün İzole Sıçan Kalp Kası Üzerine Etkileri. Yüksek Lisans Tezi, Osmangazi Üniversitesi Sağlık Bilimleri Enstitüsü, Kasım.

Balasundram, N., Sundram, K., Samman, S. 2006. Phenolic Compounds in Plants and AgriIndustrial By-Products: Antioxidant Activity, Occurrence, And Potential Uses. Food Chemistry, 99 (1): 191-203.

Baytop, T. 1984. Türkiye'de Bitkiler ile Tedavi. i..ü., Eczacılık Fakültesi Yayınları, No:40, İstanbul, 520 s.

Ceylan, A. 1983. Tıbbi Bitkiler-II. Ege Üniversitesi Ziraat Fakültesi Yayını, No:481, Bornovaİzmir.

Chou, ST., Lai, CC., Lai, CP., Chao, WW. 2018. Chemical Composition, Antioxidant, AntiMelanogenic and Antiinflammatory Activities of Glechoma hederacea (Lamiaceae) Essential Oil. Industrial Crops and Products, 122: 675-685.

Coccia, A., Carraturo, aç, Mosca, L., Masci, A., Bellini, A., Campagnaro, M., Lendaro, E. 2012. Effects of methanolic extract of sour cherry (Prunus cerasus L.) on microbial growth International Journal of Food Science and Technology, 47 (8): pp. 1620-1629.

Dadalioglu, I. ve Evrendilek, GA. 2004. Chemical Compositions and Antibacterial Effects of Essential Oils of Turkish Oregano (Origanum Minutiflorum), Bay Laurel (Laurus Nobilis), Spanish Lavender (Lavandula Stoechas L.), and Fennel (Foeniculum Vulgare) on Common Foodborne Pathogens. Journal of Agricultural and Food Chemsitry, 52(26): 8255-8260.

Damar, İ. ve Ekşi, A. 2012. Antioxidant Capacity And Anthocyanin Profile of Sour Cherry (Prunus cerasus L.) Juice. Food Chemistry, 135(4): 2910-2914.

Derwich, E., Benziane, Z., Boukir, A. 2009. Chemical Composition and Antibacterial Activity of Leaves Essential Oil of Laurus nobilis from Morocco. Australian Journal of Basic and Applied Sciences, 3(4): 3818-3824.

Dorman, HJD. ve Deans, SG. 2000. Antimicrobial Agents from Plants Antibacterial Activity of
Plant Volatile Oils. Journal of Applied Microbiology, 88(2): 308-316.

Ehivet, FE., Min, B., Park, MK., Oh, JH. 2011. Characterization and Antimicrobial Activity of Sweet Potato Starch-Based Edible Film Containing Origanum (Thymus capitatus) Oil. Journal of Food Science, 76(1): C178-184.

El Hamdaoui, A., Msanda, F., Boubaker, H., Leach, D., Bombarda, I., Vanloot, P., El Aouad,N., Abbad, A., Boudyach, EH., Achemchem, F., Elmoslih, A., Ait Ben Aoumar, A., El Mousadik. A. 2018. Essential Oil Composition, Antioxidant And Antibacterial Activities of Wild and Cultivated Lavandula mairei Humbert, Biochemical Systematics and Ecology, 76:1-7.

El-Shazly, A., Dorai, G., Wink, M. 2002. Composition and Antimicrobial Activity of Essential Oil and Hexane-Ether Extract of Tanacetum santolinoides (dc.) Feinbr. and Fertig. Zeitschrift für Naturforschung $C$, Journal of Biosciences, 57(7-8): 620-623.

Habib, M., Ibrahim, HW., Schneider-Stock, R., Hassan, HM. 2013. Camel Milk Lactoferrin Reduces The Proliferation of Colorectal Cancer Cells and Exerts Antioxidant and DNA Damage Inhibitory Activities. Food Chemistry, 141(1): 148-152.

Helander, IM., Alakomi, HL., Latva-Kala, K., Mattila, ST., Pol, I., Smid, EJ., Gorris, LG.M., Wright VA.1998. Characterisation of The Action of Selected Essential Oil Components on Gram Negative Bacteria. Journal of Agricultural and Food Chemistry, 46(9): 3590-3595.

İlçim, A., Dığrak, M., Bağcı, E. 1998. Bazı Bitki Ekstraktlarının Antimikrobiyal Etkilerinin Araştırılması. Turkish Journal of Biology, 22:119-125.

Kıvrak, Ş. 2018. Essential Oil Composition and Antioxidant Activities of Eight Cultivars of Lavender and Lavandin from Western Anatolia. Industrial Crops and Products, 117: 88-96.

Kiralan, M., Özkan, G., Bayrak, A., Ramadan, MF. 2014. Physicochemical properties and stability of black cumin seed oil as affected by different extraction methods. Industrial Crops and Products, 57: 52-60.

Kołodziejczyk, K., Sojka, M., Abadias, M., Vinas, I., Guyot, S., Baron, A. 2013. Polyphenol Composition, Antioxidant Capacity, and Antimicrobial Activity of The Extracts Obtained from Industrial Sour Cherry Pomace. Industrial Crops and Products, 51: 279-288.

Lambert, RJW., Skandamis, PN., Coote, P., Nychas, GJE. 2001. A Study of The Minimum 
Inhibitory Concentration and Mode of Action of Oregano Essential Oil, Thymol and Carvacrol. Journal of Applied Microbiology, 91(3): 453-462.

Lutterodt, H., Luther, M., Slavin, M., Yin, JJ., Parry ,J., Gao, JM., Yu, LL. 2010. Fatty Acid Profile, Thymoquinone Content, Oxidative Stability and Antioxidant Properties of Cold-Pressed Black Cumin Seed Oils. LWT - Food Science and Technology, 43(9): 1409-1413.

Mitscher, LA., Drake, S., Gollapudi, SR., Okwute,SK.1987. A Modern Look at Folkloric Use of Anti-Infective Agents. Journal of Natural Products, 50(6): 1025-1040.

Motulsky H 2007. GraphPad Prism ${ }^{\circledR}$ Version 5.0 Statistics Guide. San Diego CA, GraphPad Software. www.graphpad.com.

Oyaizu, M. 1986. Studies on Products of Browning Reaction - Antioxidative Activities of Products of Browning Reaction Prepared from Glucosamine. Japanese Journal of Nutrition, 44(6): 307-315.

Özel, N., Akkaş, ME., Akbin, G., Altun,A., Akbin, NA., Öner, HH. 2008. Batı Anadolu'da Defne (Laurus nobilis L.) Yayılış Alanlarının Yetişme Ortamı Özelliklerinin Belirlenmesi. Çevre ve Orman Bakanlığı Ege Ormancılık Araştırma Müdürlüğü Teknik Bülten No:40, Bakanlık Yayın No: 329, Müdürlük Yayın No: 39, 4-73s, İzmir.

Polyak, SJ., Morishima, C., Shuhart, MC., Wang, CC., Liu, Y., Lee, DYW.2007. Inhibition of T-Cell Inflammatory Cytokines, Hepatocyte NF-KB Signaling, and HCV Infection by Standardized Silymarin (Milk thistle). Gastroenterology, 132(5): 1925-1936.

Rainone, F. 2005. Milk thistle. American Family Physician, Volume 72 (7):1285- 1288.

Re, R., Pellegrini, N., Proteggente, A., Pannala, A., Yang, M., Rice-Evans, C. 1999. Antioxidant Activity Applying An İmproved ABTS Radical Cation Decolorization Assay. Free Radical Biology \& Medicine, 26 pp. 1231-1237.

Riu-Aumatell, M., Castellari, M., López-Tamames, Galassi, S., Buxadera, S. 2004. Characterization of Volatile Compounds of Fruit Juices and Nectars by HS/SPME and GC/MS. Food Chemistry, 87(4): 627-637.

Ronald, MA. 1990. Microbiologia, Compania Editorial Continental S.A. de C.V., Mexico DF. p. 505.

Sarikurkcu, C., Ozer, MS., Calli, N., Popovic'DJ. 2018. Essential Oil Composition and Antioxidant Activity of Endemic Marrubium parviflorum subsp. Oligodon. Industrial Crops and Products, 119: 209-213.
Sartoratto, A., Machado, A L M., Delarmelina, C., Figueira, G M., Duarte, MCT., Rehder. VLG.2004. Composition and Antimicrobial Activity of Essential Oils from Aromatic Plants Used in Brazil. Brazilian Journal of Microbiology, 35(4): 275-280.

Tim, CTP., Andrew, JL. 2005. Antimicrobial Activity of Flavonoids. International Journal of Antimicrobial Agents, 26: 343-356.

Vander Berghe, DA ve Vietinck, AJ. 1991. Screening Methods for Antibacterial and Antiviral Agents from Higger Plants. Methods in Plant Biochemistry. Academic Pres, London. (Ed) DEy, PM., Harborne, JB., chapter 3, p. 47-69.

Wagner H., Horhammer, L., Munster, R. 1968. On the Chemistry of Silymarin (Silybin), The Active Principle of The Fruits from Silybum marianum (L.) Gaertn. (Carduus marianus L.). Arzneimittelforschung, 18(6): 688-696.

Wallace, SN., Carrier, DJ., Clausen E. 2003. Extraction of Nutraceuticals from Milk Thistle: Part II. Extraction With Organic Solvents. Applied Biochemistry and Biotechnology, 108: 891-903.

Yuan, GF., Chen, XE., LI. D. 2016. Chitosan Films and Coatings Containing Essential Oils: The Antioxidant and Antimicrobial Activity, and Application in Food Systems. Food Research International, 89(1):117-128. 
Çizelge 1. Silybum marianum, Nigella sativa, Punica granatum ve Laurus nobilis yağının (distile su buharı yöntemi ve soğuk pres) antimikrobiyal aktivitesini gösteren inhibisyon bölgeleri (derişik). (MIC; $\mathrm{mg} \mathrm{ml}^{-1}$ ) uçucu yağların

\begin{tabular}{|c|c|c|c|c|c|c|c|c|c|c|c|c|c|c|c|}
\hline \multirow{2}{*}{\multicolumn{2}{|c|}{ Esansiyel Yağ }} & \multicolumn{14}{|c|}{ Mikroorganizma } \\
\hline & & $\begin{array}{l}\text { L. } \\
\text { monocytoge }\end{array}$ & E. coli & C. perfiringes & $\begin{array}{l}P . \\
\text { aeruginosa }\end{array}$ & P. vulgaris & $\begin{array}{l}\text { K. } \\
\text { pneumoniae }\end{array}$ & S. aureus & A.niger & C. albicans & B. subtilis & S. enteritidis & M. luteus & Y.enterocolitica & B. ceraus \\
\hline \multicolumn{2}{|c|}{ Silybum marianum } & Ortalama $\pm S S$ & $\begin{array}{l}\text { Ortalama } \\
\pm \mathrm{SS}\end{array}$ & Ortalama $\pm S S$ & $\begin{array}{l}\text { Ortalama } \\
\pm S S\end{array}$ & $\begin{array}{l}\text { Ortalama } \\
\pm \mathrm{SS}\end{array}$ & $\begin{array}{l}\text { Ortalama } \\
\pm S S\end{array}$ & Ortalama \pm SS & Ortalama \pm SS & Ortalama \pm SS & Ortalama \pm SS & $\begin{array}{l}\text { Ortalama } \\
\pm \mathrm{SS}\end{array}$ & $\begin{array}{l}\text { Ortalama } \\
\pm \mathrm{SS}\end{array}$ & Ortalama \pm SS & $\begin{array}{l}\text { Ortalama } \\
\pm \mathrm{SS}\end{array}$ \\
\hline \multirow[b]{2}{*}{ Alkol } & $20 \mathrm{mgml}^{-1}$ & $7.400 \pm 0.00$ & $9.110 \pm 0.00$ & $8.060 \pm 0.00$ & $7.970 \pm 0.00$ & $7.570 \pm 0.00$ & $6.570 \pm 0.00$ & $8.570 \pm 0.00$ & $9.670 \pm 0.00$ & $10.270 \pm 0.00$ & $9.840 \pm 0.00$ & $10.000 \pm 0.00$ & $7.340 \pm 0.00$ & $9.310 \pm 0.00$ & $7,280 \pm 0,00$ \\
\hline & $30 \mathrm{mgml}^{-1}$ & $7.640 \pm 0.00$ & $9.610 \pm 0.00$ & $9.010 \pm 0.00$ & $8.080 \pm 0.00$ & $7.580 \pm 0.00$ & $7.080 \pm 0.00$ & $8.880 \pm 0.00$ & $9.980 \pm 0.00$ & $10.580 \pm 0.00$ & $10.080 \pm 0.00$ & $10.280 \pm 0.00$ & $7.580 \pm 0.00$ & $9.510 \pm 0.00$ & $7,580 \pm 0,00$ \\
\hline \multirow{2}{*}{ Hekzan } & $20 \mathrm{mgml}^{-1}$ & $7.840 \pm 0.00$ & $10.240 \pm 0.00$ & $11.340 \pm 0.00$ & $11.440 \pm 0.00$ & $8.780 \pm 0.00$ & $7.580 \pm 0.00$ & $9.670 \pm 0.00$ & $12.223 \pm 0.005$ & $13.143 \pm 0.005$ & $17.140 \pm 0.005$ & $11.860 \pm 0.00$ & $9.660 \pm 0.00$ & $10.240 \pm 0.00$ & $8,360 \pm 0,00$ \\
\hline & $30 \mathrm{mgml}^{-1}$ & $8.340 \pm 0.00$ & $10.720 \pm 0.00$ & $11.940 \pm 0.00$ & $11.840 \pm 0.00$ & $8.900 \pm 0.00$ & $7.800 \pm 0.00$ & $9.770 \pm 0.00$ & $12.323 \pm 0.005$ & $13.223 \pm 0.005$ & $17.140 \pm 0.005$ & $12.140 \pm 0.00$ & $9.810 \pm 0.00$ & $10.520 \pm 0.00$ & $9,110 \pm 0,00$ \\
\hline \multicolumn{16}{|c|}{ Nigella sativa } \\
\hline \multirow{2}{*}{ Alkol } & $20 \mathrm{mgml}^{-1}$ & $6.150 \pm 0.00$ & $6.130 \pm 0.00$ & $6.700 \pm 0.00$ & $6.000 \pm 0.00$ & $6.200 \pm 0.00$ & $6.120 \pm 0.00$ & $12.810 \pm 0.005$ & $11.440 \pm 0.00$ & $11.640 \pm 0.00$ & $19.360 \pm 0.005$ & $7.180 \pm 0.00$ & $6.020 \pm 0.00$ & $7.080 \pm 0.00$ & $11,090 \pm 0,00$ \\
\hline & $30 \mathrm{mgml}^{-1}$ & $6.300 \pm 0.00$ & $6.240 \pm 0.00$ & $6.980 \pm 0.00$ & $6.000 \pm 0.00$ & $6.400 \pm 0.00$ & $6.340 \pm 0.00$ & $13.160 \pm 0.005$ & $11.400 \pm 0.00$ & $11.900 \pm 0.00$ & $19.773 \pm 0.005$ & $8.265 \pm 0.00$ & $6.230 \pm 0.00$ & $7.400 \pm 0.00$ & $11,300 \pm 0,00$ \\
\hline \multirow{2}{*}{ Hekzan } & $20 \mathrm{mgml}^{-1}$ & $12.080 \pm 0.005$ & $9.100 \pm 0.00$ & $11.330 \pm 0.00$ & $9.380 \pm 0.00$ & $10.280 \pm 0.00$ & $7.480 \pm 0.00$ & $14.540 \pm 0.005$ & $15.090 \pm 0.005$ & $14.090 \pm 0.005$ & $10.680 \pm 0.00$ & $9.180 \pm 0.00$ & $8.050 \pm 0.00$ & $8.780 \pm 0.00$ & $17,600 \pm 0,00$ \\
\hline & $30 \mathrm{mgml}^{-1}$ & $12.200 \pm 0.005$ & $9.200 \pm 0.00$ & $11.450 \pm 0.00$ & $9.520 \pm 0.00$ & $10.360 \pm 0.00$ & $7.700 \pm 0.00$ & $14.673 \pm 0.005$ & $15.373 \pm 0.005$ & $14.373 \pm 0.005$ & $10.960 \pm 0.00$ & $9.320 \pm 0.00$ & $8.300 \pm 0.00$ & $8.440 \pm 0.00$ & $17,820 \pm 0,00$ \\
\hline \multicolumn{16}{|c|}{ Punica granatum } \\
\hline \multirow{2}{*}{ Alkol } & $20 \mathrm{mgml}^{-1}$ & $6.000 \pm 0.00$ & $7.180 \pm 0.00$ & $8.500 \pm 0.00$ & $7.450 \pm 0.00$ & $6.950 \pm 0.00$ & $6.300 \pm 0.00$ & $8.190 \pm 0.00$ & $11.430 \pm 0.00$ & $11.240 \pm 0.00$ & $6.560 \pm 0.00$ & $7.350 \pm 0.00$ & $7.250 \pm 0.00$ & $6.220 \pm 0.00$ & $7.440 \pm 0,00$ \\
\hline & $30 \mathrm{mgml}^{-1}$ & $6.000 \pm 0.00$ & $7.300 \pm 0.00$ & $8.700 \pm 0.00$ & $7.600 \pm 0.00$ & $7.200 \pm 0.00$ & $6.600 \pm 0.00$ & $8.3200 \pm 0.00$ & $11.650 \pm 0.00$ & $11.400 \pm 0.00$ & $6.870 \pm 0.00$ & $7.540 \pm 0.00$ & $7.440 \pm 0.00$ & $6.430 \pm 0.00$ & $7,670 \pm 0,00$ \\
\hline \multirow{2}{*}{ Hekzan } & $20 \mathrm{mgml}^{-1}$ & $11.630 \pm 0.00$ & $8.550 \pm 0.00$ & $8.850 \pm 0.00$ & $6.000 \pm 0.00$ & $12.140 \pm 0.00$ & $9.280 \pm 0.00$ & $8.110 \pm 0.00$ & $13.560 \pm 0.005$ & $13.090 \pm 0.005$ & $10.870 \pm 0.00$ & $8.240 \pm 0.00$ & $10.290 \pm 0.00$ & $6.020 \pm 0.00$ & $8.430 \pm 0,00$ \\
\hline & $30 \mathrm{mgml}^{-1}$ & $11.850 \pm 0.00$ & $8.800 \pm 0.00$ & $9.200 \pm 0.00$ & $6.000 \pm 0.00$ & $12.400 \pm 0.00$ & $9.420 \pm 0.00$ & $8.2300 \pm 0.00$ & $14.240 \pm 0.005$ & $13.773 \pm 0.005$ & $11.340 \pm 0.00$ & $8.3300 \pm 0.00$ & $10.660 \pm 0.00$ & $6.230 \pm 0.00$ & $8,560 \pm 0,00$ \\
\hline \multicolumn{16}{|c|}{ Laurus nobilis } \\
\hline \multirow{2}{*}{ Alkol } & $20 \mathrm{mgml}^{-1}$ & $7.170 \pm 0.00$ & $9.180 \pm 0.00$ & $8.380 \pm 0.00$ & $6.715 \pm 0.00$ & $6.840 \pm 0.00$ & $6.340 \pm 0.00$ & $11.390 \pm 0.00$ & $7.415 \pm 0.00$ & $7.815 \pm 0.00$ & $14.230 \pm 0.00$ & $11.490 \pm 0.00$ & $7.770 \pm 0.00$ & $7.300 \pm 0.00$ & $8,1100 \pm 0,00$ \\
\hline & $30 \mathrm{mgml}^{-1}$ & $7.350 \pm 0.00$ & $9.420 \pm 0.00$ & $8.720 \pm 0.00$ & $7.350 \pm 0.00$ & $7.350 \pm 0.00$ & $6.650 \pm 0.00$ & $11.460 \pm 0.00$ & $7.850 \pm 0.00$ & $8.550 \pm 0.00$ & $14.350 \pm 0.00$ & $12.260 \pm 0.00$ & $7.900 \pm 0.00$ & $7.500 \pm 0.00$ & $8,2200 \pm 0,00$ \\
\hline \multirow{2}{*}{ Hekzan } & $20 \mathrm{mgml}^{-1}$ & $16.790 \pm 0.00$ & $11.430 \pm 0.00$ & $14.870 \pm 0.005$ & $12.230 \pm 0.00$ & $8.290 \pm 0.00$ & $8.540 \pm 0.00$ & $11.490 \pm 0.00$ & $11.890 \pm 0.00$ & $11.690 \pm 0.00$ & $10.480 \pm 0.00$ & $13.630 \pm 0.00$ & $8.190 \pm 0.00$ & $8.590 \pm 0.00$ & $11.880 \pm 0,00$ \\
\hline & $30 \mathrm{mgml}^{-1}$ & $16.960 \pm 0.00$ & $11.550 \pm 0.00$ & $15.023 \pm 0.005$ & $12.450 \pm 0.00$ & $8.320 \pm 0.00$ & $8.860 \pm 0.00$ & $11.760 \pm 0.00$ & $12.360 \pm 0.00$ & $12.060 \pm 0.00$ & $10.860 \pm 0.00$ & $13.850 \pm 0.00$ & $8.220 \pm 0.00$ & $8.9200 \pm 0.00$ & $12,260 \pm 0,00$ \\
\hline \multicolumn{2}{|c|}{ Ampicillin } & $28,00 \pm 0,00$ & $19.00 \pm 0.00$ & $43.16 \pm 0.028$ & $32.26 \pm 0.046$ & $29.00 \pm 0.00$ & $15.2 \pm 0.010$ & $10.0 \pm 00$ & TE & TE & $35.6 \pm 0.00$ & $35.40 \pm 0.034$ & $6.00 \pm 0.00$ & 26. ӥ66e \pm 0.57 & $26.50 \pm 0.026$ \\
\hline \multicolumn{2}{|c|}{ Cephazolin } & $33,13 \pm 0,023$ & $19.00 \pm 0.00$ & $43.16 \pm 0.028$ & $28.33 \pm 0.028$ & $6.00 \pm 0.00$ & $17.2 \pm 0.010$ & $6.00 \pm 0.00$ & TE & TE & $38.26 \pm 0.109$ & $35.16 \pm 0.040$ & $35.73 \pm 0.023$ & $34.33 c \pm 0.57$ & $28.20 \pm 0.026$ \\
\hline \multicolumn{2}{|l|}{ Nystatin } & $\mathrm{TE}$ & TE & TE & TE & TE & TE & $\mathrm{TE}$ & $17.00 \pm 0.00$ & $17.00 \pm 0.00$ & TE & TE & $\mathrm{TE}$ & TE & TE \\
\hline \multicolumn{2}{|l|}{ Solvents } & - & - & - & - & - & - & - & - & & - & - & - & - & - \\
\hline
\end{tabular}

Ortalama değerler üç ölçümün ortalaması ile hesaplanmıştır \pm SS(Standart Sapma). TE, Test edilmedi, -: Aktivite gözlenmedi. Pseudomonas aeruginosa ATCC ${ }^{27853}$ Gram (-),Proteus vulgaris ATCC ${ }^{\circledR 7829}$ Gram (). Escherichia coli ATCC ${ }^{\circledR} 25922$ Gram (-), Klebsiella pneumoniae ATCC ${ }^{\oplus} 13883$ Gram (-), Listeria monocytogenes ATCC ${ }^{\oplus 7677}$ Gram (+), Clostridium perfringens ATCC 313124 Gram (-), Salmonella enteric ATCC 14028 , Gram $(-)$, Bacillus subtilis B209, Gram (+),Streptococcus mutans RSHE 676, Gram (+), Micrococcus luteus B1018, Gram (+),Staphylococcus aureus ATCC 6538 Gram (+),Yersinia enterocolitica ATCC ${ }^{\circ 27729}$ Gram (-),Bacillus cereus ATCC ${ }^{\circledR} 10876$ Gram (+),Candida albicans ATCC ${ }^{\oplus} 10231$, Aspergillus niger ATCC 9642 
Çizelge 2. Çörek Otu (Nigella sativa $\mathrm{L}$ ) esansiyel yağının ana bileşenleri (\%)

\begin{tabular}{|c|c|c|c|c|}
\hline No & Süre & $\%$ Alan & \% Yükseklik & Adı \\
\hline 1 & 1.007 & 0.18 & 0.21 & Valeraldehyde \\
\hline 2 & 1.167 & 1.14 & 1.38 & Lactate <ethyl-> \\
\hline 3 & 1.293 & 0.82 & 1.61 & Propylene glycol \\
\hline 4 & 1.382 & 0.26 & 0.48 & Valeraldehyde $<2$-methyl-> \\
\hline 5 & 1.58 & 0.22 & 0.19 & Acetoin \\
\hline 6 & 1.726 & 0.29 & 0.62 & Acetoin \\
\hline 7 & 1.75 & 0.12 & 0.27 & Formate <hexyl-> \\
\hline 8 & 1.811 & 0.09 & 0.14 & Nonane \\
\hline 9 & 2.816 & 0.1 & 0.21 & Valeraldehyde \\
\hline 10 & 4.925 & 0.71 & 1.01 & Capronaldehyde \\
\hline 11 & 9.071 & 4.27 & 4.53 & Thujene <alpha-> \\
\hline 12 & 9.305 & 1.64 & 1.35 & Pinene <alpha-> \\
\hline 13 & 9.85 & 0.3 & 0.27 & Camphene \\
\hline 14 & 10.817 & 0.35 & 0.45 & Sabinene \\
\hline 15 & 10.916 & 1.54 & 1.3 & Pinene $<$ beta- $>$ \\
\hline 16 & 11.395 & 0.09 & 0.1 & Amyl ethyl ketone \\
\hline 17 & 11.558 & 0.53 & 0.52 & Myrcene \\
\hline 18 & 12.487 & 0.33 & 0.38 & Terpinene <alpha-> \\
\hline 19 & 12.813 & 26.77 & 28.83 & Cymene <para-> \\
\hline 20 & 12.975 & 8.27 & 7.98 & Limonene \\
\hline 21 & 13.073 & 15.58 & 10.48 & Eucalyptol \\
\hline 22 & 13.376 & 0.09 & 0.13 & Pinene <alpha-> \\
\hline 23 & 13.787 & 0.24 & 0.24 & Ocimene $<(E)-$, beta- $>$ \\
\hline 24 & 14.158 & 1.08 & 1.14 & Terpinene <gamma-> \\
\hline 25 & 15.331 & 0.33 & 0.29 & Terpinolene \\
\hline 26 & 15.642 & 0.1 & 0.17 & Sabinene hydrate <cis-> \\
\hline 27 & 15.793 & 6.61 & 5.86 & Linalool \\
\hline 28 & 16.514 & 0.57 & 0.84 & Dihydrocarveol \\
\hline 29 & 17.47 & 1.45 & 1.18 & Camphor \\
\hline 30 & 17.856 & 2.69 & 2.3 & Menthone \\
\hline 31 & 18.313 & 6.16 & 5.39 & Isoborneol \\
\hline 32 & 18.601 & 0.87 & 0.67 & Menthol \\
\hline 33 & 18.76 & 0.9 & 0.98 & Terpinen-4-ol \\
\hline 34 & 19.268 & 1.35 & 1.36 & Terpineol <alpha-> \\
\hline 35 & 19.97 & 0.23 & 0.3 & Verbenone \\
\hline 36 & 21.452 & 2.81 & 3.61 & Jasmone $<$ (Z) $>$ \\
\hline 37 & 21.692 & 0.32 & 0.36 & Linalyl acetate \\
\hline 38 & 22.801 & 2.13 & 2.54 & Bornyl acetate \\
\hline 39 & 22.988 & 0.2 & 0.23 & Carvacrol \\
\hline 40 & 23.332 & 4.45 & 5.48 & Carvacrol \\
\hline 41 & 26.176 & 0.13 & 0.19 & Geranyl acetate \\
\hline 42 & 27.017 & 0.12 & 0.16 & Aromadendrene \\
\hline 43 & 27.483 & 1.82 & 2.34 & Himachalene <alpha-> \\
\hline 44 & 30.334 & 0.1 & 0.15 & Bisabolene <beta- $>$ \\
\hline 45 & 31.699 & 0.65 & 0.89 & Acetovanillone \\
\hline 46 & 32.897 & 1 & 0.89 & Phthalate < diethyl-> \\
\hline
\end{tabular}


Çizelge 3. Defne (Laurus nobilis L) esansiyel yağının ana bileşenleri (\%)

\begin{tabular}{|c|c|c|c|c|c|c|c|c|c|}
\hline No & Ret. Time & $\%$ Area & \% Height & Name & No & Ret. Time & $\%$ Area & \% Height & Name \\
\hline 1 & 1.076 & 0.14 & 0.18 & Valeraldehyde & 35 & 16.95 & 1.33 & 1.12 & Terpinolene \\
\hline 2 & 1.158 & 0.11 & 0.15 & Valeraldehyde & 36 & 17.401 & 1.44 & 1.32 & Terpinene <alpha-> \\
\hline 3 & 1.233 & 0.14 & 0.23 & Propylene glycol & 37 & 17.5 & 0.79 & 0.52 & Camphor \\
\hline 4 & 1.316 & 0.83 & 0.93 & Piruvate <ethyl-> & 38 & 17.875 & 0.81 & 0.63 & Menthone \\
\hline 5 & 1.402 & 0.37 & 0.95 & Piruvate <ethyl-> & 39 & 18.326 & 1.54 & 1.14 & Isoborneol \\
\hline 6 & 1.436 & 0.18 & 0.46 & Lactate <ethyl-> & 40 & 18.6 & 0.17 & 0.1 & Menthol \\
\hline 7 & 1.883 & 8.77 & 3.81 & Acetoin & 41 & 18.762 & 0.38 & 0.42 & Terpinen-4-ol \\
\hline 8 & 1.956 & 0.19 & 0.4 & Piruvate <ethyl-> & 42 & 19.269 & 0.56 & 0.69 & Terpineol <alpha-> \\
\hline 9 & 2.75 & 0.09 & 0.1 & Valeraldehyde & 43 & 19.549 & 0.27 & 0.28 & Anisole <para-allyl-> \\
\hline 10 & 2.833 & 0.16 & 0.31 & Valeraldehyde & 44 & 21.236 & 0.1 & 0.12 & Carvone \\
\hline 11 & 4.885 & 0.18 & 0.34 & Capronaldehyde & 45 & 21.572 & 0.33 & 0.33 & Anisaldehyde <para-> \\
\hline 12 & 4.935 & 1.12 & 1.52 & Capronaldehyde & 46 & 22.758 & 2.31 & 1.61 & Anethole $<(E)->$ \\
\hline 13 & 9.082 & 0.48 & 0.58 & Thujene <alpha-> & 47 & 23.331 & 1.25 & 1.47 & Carvacrol \\
\hline 14 & 9.307 & 6.74 & 6.5 & Pinene <alpha-> & 48 & 23.901 & 0.16 & 0.21 & Terpinyl acetate <alpha-> \\
\hline 15 & 9.843 & 0.64 & 0.63 & Camphene & 49 & 24.139 & 0.13 & 0.17 & Pelargol \\
\hline 16 & 10.83 & 1.73 & 2.04 & Sabinene & 50 & 24.77 & 0.1 & 0.11 & Limonene oxide <cis-> \\
\hline 17 & 10.925 & 3.51 & 4.1 & Pinene <beta-> & 51 & 24.856 & 0.16 & 0.2 & $\begin{array}{l}\text { Hex-2-enal <2-isopropyl-, 5- } \\
\text { methyl-> }\end{array}$ \\
\hline 18 & 11.424 & 0.27 & 0.34 & $\begin{array}{l}\text { Hept-5-en-2-one <6-methyl- } \\
>\end{array}$ & 52 & 25.028 & 2.94 & 3.62 & Terpinyl acetate <alpha-> \\
\hline 19 & 11.574 & 4.36 & 4.49 & Myrcene & 53 & 25.13 & 0.12 & 0.15 & Nonane-1,3-diol acetate \\
\hline 20 & 12.03 & 6.77 & 8.22 & Phellandrene <alpha-> & 54 & 25.831 & 0.22 & 0.27 & Copaene <alpha-> \\
\hline 21 & 12.253 & 0.12 & 0.14 & Carene <delta-3-> & 55 & 26.529 & 1.97 & 2.51 & Elemene <beta-> \\
\hline 22 & 12.513 & 0.63 & 0.65 & Terpinene <alpha-> & 56 & 27.476 & 0.74 & 0.89 & Himachalene <alpha-> \\
\hline 23 & 12.824 & 4.93 & 4.78 & Cymene <para-> & 57 & 28.088 & 0.29 & 0.36 & Bulnesene <alpha-> \\
\hline 24 & 12.997 & 9.99 & 10.11 & Sabinene & 58 & 28.242 & 0.15 & 0.19 & Muurolene <alpha-> \\
\hline 25 & 13.079 & 14.82 & 13.77 & Eucalyptol & 59 & 28.437 & 0.11 & 0.13 & Gurjunene <alpha-> \\
\hline 26 & 13.399 & 0.53 & 0.62 & Pinene <alpha-> & 60 & 28.601 & 0.14 & 0.17 & Humulene <alpha-> \\
\hline 27 & 13.808 & 7.7 & 9.75 & Ocimene $<(E)-$, beta- $>$ & 61 & 29.674 & 0.28 & 0.33 & Selinene <beta-> \\
\hline 28 & 14.182 & 0.6 & 0.61 & Terpinene <gamma-> & 62 & 29.957 & 0.24 & 0.28 & Selinene <beta-> \\
\hline 29 & 15.344 & 0.51 & 0.33 & Terpinolene & 63 & 30.288 & 0.19 & 0.18 & Bulnesene <alpha-> \\
\hline 30 & 15.51 & 0.29 & 0.27 & Terpineol <trans-, beta-> & 64 & 30.545 & 0.14 & 0.17 & Cadinene <gamma-> \\
\hline 31 & 15.821 & 2.87 & 2.15 & Linalool & 65 & 30.832 & 0.13 & 0.13 & Cadinene <delta-> \\
\hline 32 & 15.979 & 0.42 & 0.35 & Furan <2-acetyl-, 5-methyl-> & & & & & \\
\hline 33 & 16.297 & 0.13 & 0.15 & Cyclohexaneethyl acetate & & & & & \\
\hline 34 & 16.633 & 0.19 & 0.22 & Hydrocinnamaldehyde & & & & & \\
\hline
\end{tabular}


Çizelge 4. Silybum marianum L esansiyel yağının ana bileşenleri (\%)

\begin{tabular}{|c|c|c|c|c|c|c|c|c|c|c|c|c|c|c|}
\hline No & $\begin{array}{l}\text { Ret. } \\
\text { Time } \\
\end{array}$ & $\begin{array}{l}\% \\
\text { Area }\end{array}$ & $\begin{array}{l}\% \\
\text { Height }\end{array}$ & Name & No & $\begin{array}{l}\text { Ret. } \\
\text { Time }\end{array}$ & $\begin{array}{l}\% \\
\text { Area }\end{array}$ & $\begin{array}{l}\% \\
\text { Height }\end{array}$ & Name & No & $\begin{array}{l}\text { Ret. } \\
\text { Time }\end{array}$ & $\begin{array}{l}\% \\
\text { Area }\end{array}$ & $\begin{array}{l}\% \\
\text { Height }\end{array}$ & Name \\
\hline 1 & 0.127 & 5.6 & 1.49 & Tridec-2(E)-enal & 41 & 12.548 & 0.37 & 0.17 & Linalool & 81 & 33.12 & 0.47 & 0.46 & Hexadecane \\
\hline 2 & 1.135 & 0.3 & 0.38 & Valeraldehyde & 42 & 12.859 & 0.92 & 0.91 & Cymene <para-> & 82 & 33.327 & 0.1 & 0.06 & $\begin{array}{l}\text { Caprylic acid <4- } \\
\text { ethyl-> }\end{array}$ \\
\hline 3 & 1.19 & 0.39 & 0.5 & Valeraldehyde & 43 & 13.025 & 1.31 & 1.49 & Limonene & 83 & 33.508 & 0.55 & 0.62 & Tetradecanal \\
\hline 4 & 1.291 & 2.02 & 3.56 & Propylene glycol & 44 & 13.102 & 0.31 & 0.35 & Hexanol <2-ethyl-> & 84 & 33.95 & 0.1 & 0.09 & Lauric acid \\
\hline 5 & 1.344 & 1.77 & 3.98 & Propylene glycol & 45 & 13.16 & 0.14 & 0.17 & Eucalyptol & 85 & 34.041 & 0.39 & 0.32 & Diphenylketone \\
\hline 6 & 1.435 & 0.23 & 0.55 & Piruvate <ethyl-> & 46 & 13.234 & 0.14 & 0.11 & Benzyl alcohol & 86 & 34.24 & 4.42 & 4.62 & Ethylene brassylate \\
\hline 7 & 1.458 & 0.49 & 0.61 & Propylene glycol & 47 & 13.438 & 0.1 & 0.09 & Pinene <alpha-> & 87 & 34.477 & 0.15 & 0.12 & Eicosane \\
\hline 8 & 1.711 & 0.29 & 0.41 & Isovaleric acid & 48 & 14.202 & 0.19 & 0.19 & Linalyl acetate & 88 & 34.552 & 0.11 & 0.09 & Hexadecane \\
\hline 9 & 1.806 & 2.37 & 2.64 & Acetoin & 49 & 15.396 & 0.2 & 0.15 & $\begin{array}{l}\text { Dimethylstyrene } \\
<\text { <alpha-para-> }\end{array}$ & 89 & 34.879 & 0.19 & 0.13 & Disulfide <allyl-> \\
\hline 10 & 1.866 & 7.06 & 9.37 & Acetylvaleryl & 50 & 15.606 & 0.1 & 0.09 & Clorius & 90 & 35.284 & 0.98 & 0.85 & $\begin{array}{l}\text { Fenchyl acetate } \\
\text { <endo-> }\end{array}$ \\
\hline 11 & 1.99 & 2.86 & 1.72 & $\begin{array}{l}\text { Acetate } \\
<\text { <isopropyl-> }\end{array}$ & 51 & 15.823 & 6.01 & 7.12 & Linalool & 91 & 35.368 & 1.13 & 0.85 & $\begin{array}{l}\text { Angelate <isobutyl- } \\
>\end{array}$ \\
\hline 12 & 2.33 & 0.23 & 0.18 & $\begin{array}{l}\text { Nona-2(E),6(E)- } \\
\text { dienal }\end{array}$ & 52 & 15.991 & 0.91 & 0.74 & Pelargonaldehyde & 92 & 35.773 & 0.76 & 0.75 & $\begin{array}{l}\text { Cadina-1(6),4-diene } \\
<10 \text { betaH-> }\end{array}$ \\
\hline 13 & 2.43 & 0.13 & 0.17 & Sclerosol & 53 & 17.887 & 0.91 & 0.91 & Menthone & 93 & 35.87 & 0.25 & 0.26 & Ambroxide \\
\hline 14 & 2.48 & 0.25 & 0.18 & Butyl alcohol & 54 & 18.116 & 0.16 & 0.15 & Non-2(E)-enal & 94 & 36.054 & 0.33 & 0.33 & Heptadecane \\
\hline 15 & 2.592 & 0.15 & 0.1 & Capryl alcohol & 55 & 18.305 & 0.34 & 0.23 & Menthone & 95 & 36.238 & 0.4 & 0.34 & $\begin{array}{l}\text { Undecanal <2- } \\
\text { methyl-> }\end{array}$ \\
\hline 16 & 2.763 & 0.31 & 0.26 & Propionic acid & 56 & 18.628 & 0.25 & 0.19 & Menthol & 96 & 36.419 & 0.17 & 0.13 & $\begin{array}{l}\text { Benzoate <isoamyl- } \\
>\end{array}$ \\
\hline 17 & 2.875 & 0.35 & 0.33 & Valeraldehyde & 57 & 18.804 & 0.25 & 0.25 & Terpinen-4-ol & 97 & 36.966 & 0.14 & 0.12 & $\begin{array}{l}\text { Undecadienal }<2,4- \\
\text { trans, trans-> }\end{array}$ \\
\hline 18 & 4.169 & 7.67 & 6.84 & Phenethyl alcohol & 58 & 18.941 & 0.17 & 0.13 & $\begin{array}{l}\text { Azanaphthalene }<1 \text { - } \\
>\end{array}$ & 98 & 37.149 & 0.12 & 0.12 & Isobutyric acid \\
\hline 19 & 4.59 & 0.11 & 0.12 & Butyric acid & 59 & 19.309 & 0.77 & 0.87 & Terpineol <alpha-> & 99 & 37.281 & 0.12 & 0.08 & Pentacosane \\
\hline 20 & 4.978 & 2.61 & 2.87 & Capronaldehyde & 60 & 19.387 & 0.21 & 0.19 & Butyrate <hexyl-> & 100 & 38.042 & 0.16 & 0.1 & $\begin{array}{l}\text { Bergamotol }<\text { (Z)-, } \\
\text { alpha-trans-> }\end{array}$ \\
\hline 21 & 5.167 & 0.39 & 0.33 & $\begin{array}{l}\text { Cyclohexanone } \\
<4 \text {-methyl-> }\end{array}$ & 61 & 19.866 & 0.46 & 0.47 & Capraldehyde & 101 & 38.848 & 0.12 & 0.11 & Eicosane \\
\hline 22 & 5.392 & 0.13 & 0.12 & $\begin{array}{l}\text { Cyclohexanone } \\
<4 \text {-methyl-> }\end{array}$ & 62 & 21.49 & 0.18 & 0.09 & Lavandulyl acetate & 102 & 39.298 & 0.34 & 0.3 & Tetradecanal \\
\hline 23 & 5.942 & 0.18 & 0.19 & Furfural & 63 & 21.733 & 0.45 & 0.45 & Linalyl acetate & 103 & 39.721 & 0.12 & 0.09 & Isobutyric acid \\
\hline 24 & 7.088 & 0.21 & 0.18 & $\begin{array}{l}\text { Isovalerate } \\
\text { <benzyl-> }\end{array}$ & 64 & 23.038 & 0.09 & 0.09 & Carvacrol & 104 & 39.807 & 0.37 & 0.31 & $\begin{array}{l}\text { Tetralin <6-Acetyl-, } \\
1,1,2,4,4,7- \\
\text { hexamethyl-> }\end{array}$ \\
\hline 25 & 7.172 & 0.32 & 0.29 & Formate <hexyl- $>$ & 65 & 23.37 & 1.23 & 1.24 & Carvacrol & 105 & 40.328 & 0.22 & 0.19 & $\begin{array}{l}\text { Curcumene <alpha- } \\
>\end{array}$ \\
\hline 26 & 7.592 & 0.12 & 0.09 & Valeric acid & 66 & 23.561 & 0.11 & 0.1 & Tridecylaldehyde & 106 & 40.568 & 0.11 & 0.08 & Citrate <triethyl-> \\
\hline 27 & 7.797 & 0.16 & 0.14 & Styrene & 67 & 25.128 & 0.12 & 0.07 & Triacetin & 107 & 40.912 & 0.24 & 0.2 & Lilial \\
\hline 28 & 7.888 & 0.14 & 0.1 & $\begin{array}{l}\text { Heptyl methyl } \\
\text { ketone }\end{array}$ & 68 & 25.879 & 0.16 & 0.13 & |sobutyrate <buty|-> & 108 & 41.078 & 5.72 & 6.18 & $\begin{array}{l}\text { Angelate <isobutyl- } \\
>\end{array}$ \\
\hline 29 & 8.226 & 0.1 & 0.1 & Enanthaldehyde & 69 & 26.77 & 0.16 & 0.15 & Tetradecane & 109 & 41.241 & 0.1 & 0.08 & Copaene <alpha-> \\
\hline 30 & 8.416 & 0.1 & 0.12 & $\begin{array}{l}\text { Benzaldehyde } \\
<2,4 \text {-dimethyl-> }\end{array}$ & 70 & 27.064 & 0.91 & 0.87 & Lauric aldehyde & 110 & 41.477 & 0.18 & 0.13 & $\begin{array}{l}\text { Linalool } \\
<\text { tetrahydro-> }\end{array}$ \\
\hline 31 & 8.469 & 0.12 & 0.12 & $\begin{array}{l}\text { Propionate } \\
\text { <isobutyl-> }\end{array}$ & 71 & 27.185 & 0.12 & 0.1 & Disulfide <allyl-> & 111 & 41.65 & 6.13 & 6.49 & $\begin{array}{l}\text { Undecanal }<2- \\
\text { methyl-> }\end{array}$ \\
\hline 32 & 10.254 & 0.23 & 0.27 & Hept-2(E)-enal & 72 & 27.536 & 0.29 & 0.32 & Aromadendrene & 112 & 42.178 & 0.17 & 0.17 & $\begin{array}{l}\text { Palmitate <methyl- } \\
>\end{array}$ \\
\hline 33 & 10.341 & 0.48 & 0.37 & Benzaldehyde & 73 & 28.527 & 0.11 & 0.12 & Isopulegyl acetate & 113 & 44.649 & 0.22 & 0.22 & $\begin{array}{l}\text { Palmitate } \\
\text { <isopropyl-> }\end{array}$ \\
\hline 34 & 11.2 & 0.25 & 0.26 & Hepten-3-ol & 74 & 29.027 & 0.42 & 0.4 & Ionone $<(\mathrm{E})-$, beta-> & 114 & 46.277 & 8.07 & 8.02 & $\begin{array}{l}\text { Angelate <isobutyl- } \\
>\end{array}$ \\
\hline 35 & 11.263 & 0.47 & 0.37 & Oxybenzene & 75 & 30.038 & 0.15 & 0.15 & Pentadecane & 115 & 46.486 & 0.45 & 0.38 & Pentadecanolide \\
\hline 36 & 11.49 & 0.22 & 0.17 & Tridecane & 76 & 30.379 & 0.15 & 0.12 & Civetone & 116 & 48.27 & 0.1 & 0.07 & Benzyl benzoate \\
\hline 37 & 11.623 & 0.52 & 0.36 & Myrcene & 77 & 31.839 & 0.1 & 0.07 & Eicosane & 117 & 48.763 & 0.09 & 0.1 & Docosane \\
\hline 38 & 11.83 & 0.11 & 0.09 & Hexanol <ethyl-> & 78 & 32.006 & 0.09 & 0.07 & Docosane & 118 & 51.019 & 4.22 & 4.19 & $\begin{array}{l}\text { Angelate <isobutyl- } \\
>\end{array}$ \\
\hline 39 & 12.063 & 0.35 & 0.25 & Caprylaldehyde & 79 & 32.306 & 0.12 & 0.12 & Isobutyric acid & 119 & 53.186 & 0.09 & 0.08 & Heneicosane \\
\hline 40 & 12.305 & 2.39 & 2.1 & $\begin{array}{l}\text { Propionate <ethyl- } \\
\text { 3-(methylthio)-> }\end{array}$ & 80 & 33.014 & 0.54 & 0.26 & Phthalate <diethyl-> & & & & & \\
\hline
\end{tabular}


Çizelge 5. Vişne Çekirdeği Prunus cerasus L esansiyel yağının ana bileşenleri (\%)

\begin{tabular}{|c|c|c|c|c|}
\hline No & Ret. Time & \% Area & \% Height & Name \\
\hline 1 & 1.663 & 1.29 & 1.13 & Acetoin \\
\hline 2 & 1.743 & 0.35 & 0.57 & Acetoin \\
\hline 3 & 2.617 & 0.32 & 0.46 & Valeraldehyde \\
\hline 4 & 9.005 & 0.16 & 0.26 & Thujene <alpha-> \\
\hline 5 & 9.057 & 0.19 & 0.38 & Thujene <alpha-> \\
\hline 6 & 9.291 & 3.1 & 2.87 & Pinene <alpha-> \\
\hline 7 & 9.825 & 0.97 & 1.14 & Camphene \\
\hline 8 & 10.262 & 4.79 & 6.1 & Benzaldehyde \\
\hline 9 & 10.909 & 3.58 & 3.91 & Pinene <beta-> \\
\hline 10 & 11.095 & 1.18 & 1.35 & Vinyl amyl carbinol \\
\hline 11 & 11.359 & 1.13 & 1.9 & Amyl ethyl ketone \\
\hline 12 & 11.551 & 4.39 & 6.68 & Myrcene \\
\hline 13 & 12.224 & 0.28 & 0.41 & Carene $<$ delta-3-> \\
\hline 14 & 12.479 & 0.48 & 0.67 & Terpinene <alpha-> \\
\hline 15 & 12.804 & 5.1 & 5.79 & Cymene <para-> \\
\hline 16 & 13.104 & 30.9 & 20.52 & Eucalyptol \\
\hline 17 & 13.374 & 2.99 & 2.26 & Pinene <alpha-> \\
\hline 18 & 13.769 & 1.44 & 1.61 & Ocimene $<(E)-$, beta- $>$ \\
\hline 19 & 14.153 & 1.37 & 1.62 & Terpinene <gamma-> \\
\hline 20 & 15.316 & 0.71 & 0.86 & Terpinolene \\
\hline 21 & 15.785 & 2.97 & 3.15 & Linalool \\
\hline 22 & 16.927 & 0.39 & 0.46 & Terpinolene \\
\hline 23 & 17.453 & 2.1 & 1.83 & Camphor \\
\hline 24 & 17.836 & 0.97 & 0.78 & Menthone \\
\hline 25 & 18.333 & 5.74 & 6.35 & Isoborneol \\
\hline 26 & 18.62 & 0.53 & 0.54 & Pinocamphone <cis-> \\
\hline 27 & 18.757 & 1.05 & 1.45 & Terpinen-4-ol \\
\hline 28 & 19.271 & 2.02 & 2.77 & Terpineol <alpha-> \\
\hline 29 & 19.953 & 0.47 & 0.67 & Verbenone \\
\hline 30 & 21.687 & 0.18 & 0.27 & Linalyl acetate \\
\hline 31 & 22.806 & 3.23 & 4.36 & Bornyl acetate \\
\hline 32 & 22.997 & 0.21 & 0.29 & Carvacrol \\
\hline 33 & 23.376 & 5.15 & 6.4 & Carvacrol \\
\hline 34 & 27.51 & 4.82 & 6.55 & Himachalene <alpha-> \\
\hline 35 & 28.611 & 0.28 & 0.42 & Humulene <alpha-> \\
\hline 36 & 30.336 & 0.18 & 0.3 & Bisabolene <beta-> \\
\hline 37 & 32.427 & 1.71 & 0.67 & Phthalate < diethyl-> \\
\hline 38 & 32.635 & 1.34 & 0.68 & Phthalate < diethyl-> \\
\hline 39 & 32.737 & 0.89 & 0.87 & Caryophyllene oxide \\
\hline 40 & 32.855 & 1.05 & 0.7 & Phthalate < diethyl-> \\
\hline
\end{tabular}

Çizelge 6. Farklı yöntemlerle elde edilmiş uçucu yağ ekstraktlarının antioksidan aktiviteleri

\begin{tabular}{|c|c|c|c|}
\hline Numuneler & $\begin{array}{l}\text { DPPH (\% } \\
\text { iNHBISYON) }\end{array}$ & $\begin{array}{l}\text { FRAP } \\
\text { ( } \mu \mathrm{mol} \mathrm{TX} \mathrm{g}^{-1} \text { yağ) }\end{array}$ & $\begin{array}{l}\text { ABTS } \\
\text { ( } \mu \mathrm{mol} \mathrm{TX} \mathrm{g}^{-1} \text { yağ) }\end{array}$ \\
\hline Deve dikeni & 12.04 & 28.13 & 12.87 \\
\hline \multicolumn{4}{|l|}{ Silybum marianum } \\
\hline Çörek otu & 30.74 & 14.96 & 53.07 \\
\hline \multicolumn{4}{|l|}{ Nigella sativa } \\
\hline Defne tohumu Laurus nobilis & 40.76 & 8.53 & 63.93 \\
\hline Vişne tohumu Prunus cerasus & - & - & 19.16 \\
\hline
\end{tabular}

